\title{
Etude de la Performance Economique de la Replantation Annuelle De Bananiers Plantain, Une Strategie De Gestion des Nematodes au Sud de la Cote D'ivoire
}

\author{
Vawa Otro Serge Théodore \\ Gnonhouri Goly Philippe \\ Centre National de Recherche Agronomique (CNRA), \\ Station de Recherche de Bimbresso, Abidjan, Côte d'Ivoire \\ Seri Serge Pacôme \\ Université Félix Houphouët Boigny, UFR Bioscience, \\ Abidjan, Côte d'Ivoire
}

Doi:10.19044/esj.2021.v17n34p55

Submitted: 23 June 2021

Accepted: 09 August 2021

Published: 30 September 2021
Copyright 2021 Author(s)

Under Creative Commons BY-NC-ND 4.0 OPEN ACCESS

Cite As:

Théodore V.O.S., Philippe G.G. \& Pacôme S.S. (2021). Etude de la Performance Economique de la Replantation Annuelle De Bananiers Plantain, Une Strategie De Gestion des Nematodes au Sud de la Cote D'ivoire. European Scientific Journal, ESJ, 17(34), 55.

https://doi.org/10.19044/esj.2021.v17n34p55

\section{Résumé}

Les présents travaux ont été menés dans le cadre de l'accroissement durable de la production de bananier plantain et de la stratégie de sécurité alimentaire en Côte d'ivoire. Dans cette perspective, la gestion culturale des nématodes phytoparasites par la replantation annuelle de la culture de bananiers plantains a été évaluée. En condition de culture de contre saison, la variété CORNE 1 a été plantée à haute densité (2500 plants/ha) dans un dispositif impliquant quatre traitements : culture continue sans nématicide, culture continue avec nématicide, culture replantée avec nématicide et culture replantée sans nématicide. La replantation a eu lieu à $0,8 \mathrm{~m}$ du pied fructifère de la saison de culture qui a été déraciné avec les rejets successeurs. L'essai a duré trois cycles de culture. La culture replantée a permis d'obtenir des rendements élevés, 35,08 t/ha et 34,26 t/ha respectivement au 2ème et 3ème cycle de culture. Les rendements en culture replantés sont statistiquement comparables à celui obtenu à la première année de culture (35 t/ha). Par contre, en culture continue, des baisses de rendements de $41,4 \%$ et $63,5 \%$ ont été enregistrées respectivement au 2ème et 3ème cycle de culture. Par rapport à la 
culture continue, la replantation annuelle a généré une marge bénéficiaire brute de plus de $64 \%$ et $207 \%$ respectivement au 2ème et 3ème saison de culture. En définitive, la culture replantée semble économiquement plus rentable que la culture pluriannuelle de bananier plantain.

Mots clés : Phytonématodes, Nématicides, Culture Continue, Replantation Annuelle, Marge Bénéficiaire, Côte d’Ivoire

\title{
Study of The Economic Performance of Annual Plantain Replanting, A Nematode Management Strategy in Southern Cote D'ivoire
}

\author{
Vawa Otro Serge Théodore \\ Gnonhouri Goly Philippe \\ Centre National de Recherche Agronomique (CNRA), \\ Station de Recherche de Bimbresso, Abidjan, Côte d'Ivoire \\ Seri Serge Pacôme \\ Université Félix Houphouët Boigny, UFR Bioscience, \\ Abidjan, Côte d'Ivoire
}

\section{Abstract}

The work herein reported has been conducted in the framework of the sustainable improvement of production of plantain and the food security strategy of the Côte d'Ivoire. In this perspective, the annual replanting of plantain orchards has been assessed as a tool for cultural management of plantparasitic nematodes. The cultivar Horne 1 has been planted at high density (2500 plants/ha) in the framework of an off-season production system. Four treatments were applied: three continuous cycles with no nematicide application; three continuous cycles with applications of nematicide; annual replanting with nematicide applied and annual replanting with no nematicide application. Replanting was done at $0.8 \mathrm{~m}$ from the bunch bearing-tree of the previous crop that was totally uprooted after harvest. In general, the populations of R. similis and P. coffeae were concentrated (80 \%) within a radius of $50 \mathrm{~cm}$ around the bunch bearing-plantain. The lowest nematode infestations were recorded under annual planting replanting with or without nematicide treatments. In addition, yields remained high $(\mathrm{P}<0.05)$ during the second (35 t/ha) and third crops (30 t/ha) and were not statistically different from that of the first crop (35 t/ha). On the contrary, under successive crop cycles, yields declined by 41.4 and $63.5 \%$ respectively during the second and third crop cycles. Compared to the classic plantain cultivation method, annual replanting has generated a gross margin of $64 \%$ and $207 \%$ during the second 
and third seasons. Finally, the replanted crop appears to be economically more profitable than the multi-year plantain crop.

Keywords: Phytonematodes, Nematicides, Crop Cycles, Annual Replanting, Profit Margin, Côte d'Ivoire

\section{Introduction}

Le bananier est une plante annuelle. Le passage d'un cycle de production à un autre, se fait par le choix d'un rejet successeur. De telle pratique culturale, à partir de rejets aux faibles potentiels de production conduit à un déclin de la production d'un cycle de production à un autre et favorise un accroissement de la pression parasitaire (Vawa et al., 2015). Dans ces conditions, la densité de plantation n'atteint guère 1667 plants/ha et les rendements obtenus sont faibles variant entre 5 et 10 t/ha (Kobenan et $a l$., 2006). Les plantations sont hétérogènes ce qui engendre une production disparate, non homogène. Ces pratiques culturales engendrent des dates de récolte des régimes de bananiers qui ne sont pas planifiées et échelonnées. Ce handicap crée un risque d'écoulement des régimes, de mévente de la production et des pertes énormes pour les agriculteurs. Ces techniques de production combinées à la rareté des pluies, entrainent la fluctuation de l'offre de la banane plantain sur les marchés nationaux et sous régionaux qui se caractérise par une abondance de la production d'Octobre à Avril et une pénurie de Mai à Septembre, occasionnant une hausse de plus de 49-\% des prix (N’kendah et Akeampong, 2003 ; Gnonhouri, 2015). Les plantations dans ces conditions sont en général créées à partir des rejets aux faibles potentiels de production et demeurent en place pendant plusieurs cycles de culture sans mesures phytosanitaires (Vawa et al., 2015). Cette pratique culturale favorise un accroissement des phytonématodes et des pertes de production variant entre $30 \%$ et $75 \%$ (Sarah, 2000). La lutte contre ces nématodes est essentiellement chimique, avec le recours en quantité énorme de nématicides (15 kg à $20 \mathrm{~kg}$ de matière active /an). La plupart de ces nématicides sont des biocides généraux (Sarah, 1989) et entraînent des risques de pollution des milieux naturels. Ils constituent des dangers potentiels pour les populations et les animaux. Dans un tel contexte de faible rendement et de pollution de l'environnement, des techniques novatrices de culture écologique s'imposent. La replantation annuelle de bananier plantain, à base de vivoplants, se faisant sans usage de nématicides, permet de réduire de $70 \%$ les populations de nématodes à la floraison et d'avoir des rendements de plus de $35 \mathrm{t} / \mathrm{ha}$ à la première saison de culture (Bélalcazar et Cayon, 2001). Ce triple avantage de la replantation annuelle permet d'établir une marge bénéficiaire comparativement à la culture continue. La présente étude vise à étudier la 
performance économique générée par la technique de culture de bananiers replantées comparativement à la technique de culture continue pluriannuelle.

\section{Présentation du milieu d'études}

L'étude s'est déroulée dans la région de l'Agneby-Tiassa, dans le Département de Tiassalé, à Tabouatien (Figure 1). La localité de Tabouatien est située au Sud de la Côte d'Ivoire, à environ $120 \mathrm{~km}$ au Nord d'Abidjan (Monnier, 1983), entre les Latitudes Nord 556’53,4" ; 556’51,1" et les Longitudes Ouest $4^{\circ} 51^{\prime} 06,6^{\prime \prime} ; 4^{\circ} 51^{\prime} 06,7^{\prime \prime}$ et à 50,5 $\pm 0,5 \mathrm{~m}$ d'altitude. Elle se situe à la fin de la région des Lagunes et marque la fin du « V » Baoulé au Sud. Le Département de Tiassalé est situé à équidistance des deux capitales, (120 km de Yamoussoukro et d'Abidjan). Il est limité au Nord par ceux de Toumodi et de Bongouanou, à l'Est par celui d'Agboville, à l'Ouest par ceux de Taabo et de Divo et enfin au Sud par ceux de Grand-Lahou et de Sikensi. La parcelle expérimentale, ayant fait l'objet d'étude se situe dans la forêt humide semi décidue du domaine Guinéen caractérisée par un climat de type Sub-équatorial (Monnier, 1983). La température annuelle moyenne a été de $26,99 \pm 1,28^{\circ} \mathrm{C}$. Les hauteurs de pluie moyennes mensuelles ont été de 128,83 $\pm 104,01 \mathrm{~mm}$. L'humidité relative moyenne de l'air ambiante a été de $85 \pm 1,5$ $\%$.

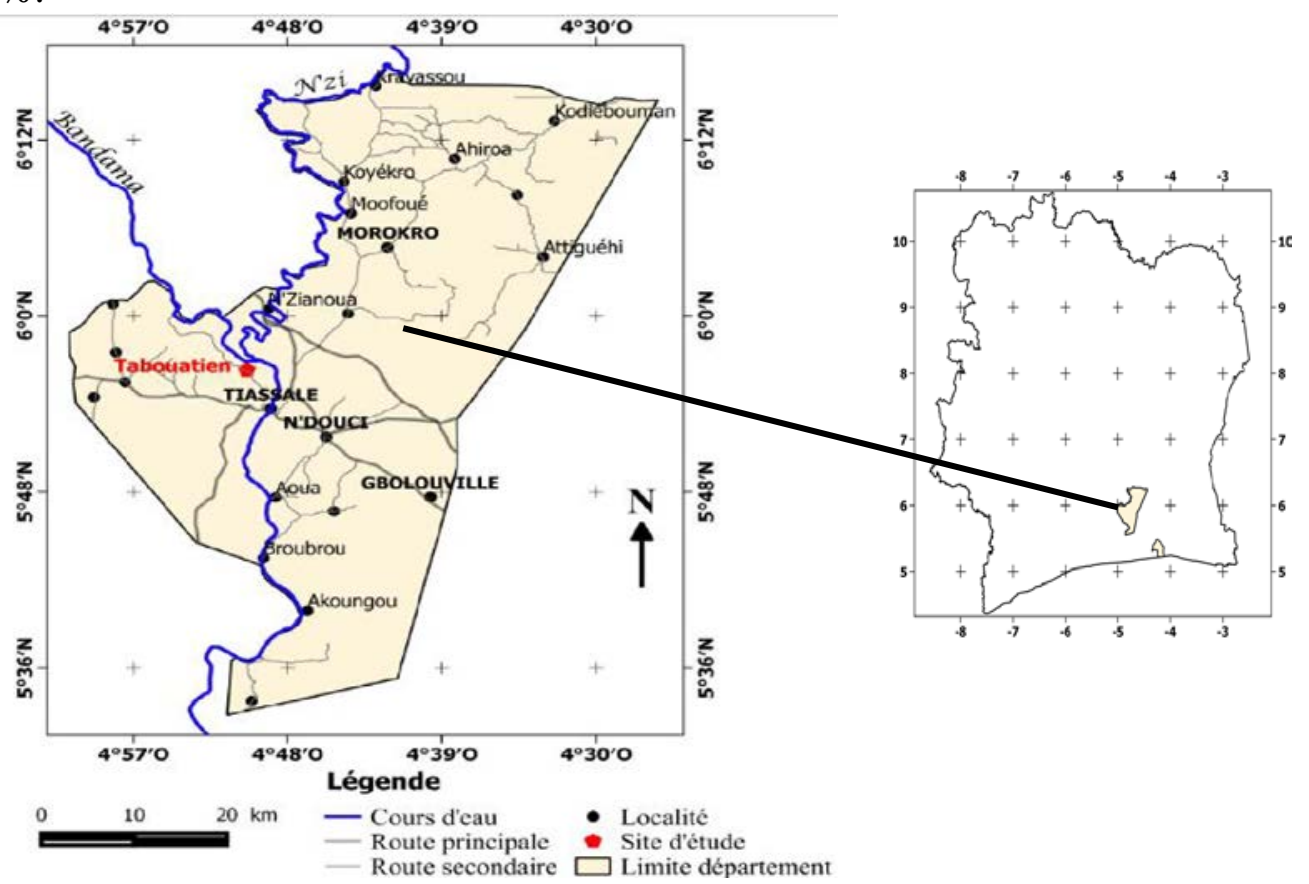

Figure 1. Localisation du site d'étude de Tabouatien (Vawa, 2015) 


\section{Matériel et méthodes \\ II.1. Matériel \\ II.1.1. Matériel végétale}

Le matériel végétal de plantation est constitué de vivoplant du cultivar CORNE 1 (Figure 2). Il est originaire de la Côte d'Ivoire. Il est du groupe génomique $\mathrm{AAB}$ et du groupe variétal FAUX CORNE. Il est issu d'un croisement de Musa accuminata AA et de Musa balbisiana (Thiemele et al., 2015). C’est une variété locale, majoritairement cultivée en zone humide et consommée en Côte d'ivoire. Le choix du cultivar CORNE 1 s'explique par le fait qu'il représente plus de $80 \%$ de la production nationale de bananiers plantain et sa culture est favorable aux conditions pédoclimatiques de la Côte d'Ivoire (N'da, 1993). De plus, ses fruits, se prêtent à plusieurs mets en Côte d'Ivoire. La floraison survient sept (7) à huit (8) mois après plantation et la durée du cycle de production est d'environ 12 mois (Thiemele et al., 2015).

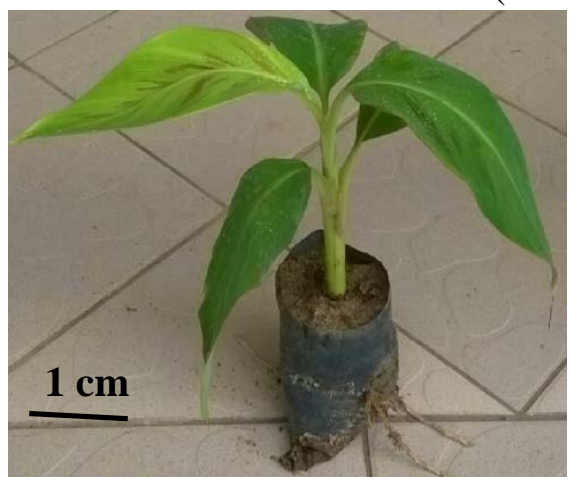

Figure 2. Cultivar de bananier CORNE 1 au stade vivoplant

\section{II.1.2. Matériel parasitaire}

Les nématodes étudiés sont Radopholus similis et Pratylenchus coffeae. Ces deux nématodes endoparasites migrateurs font tout leur cycle de vie à l'intérieur de la cellule parasitée et représentent à eux seuls plus de $60 \%$ de la nématofaune rencontrée dans les plantations de bananiers en Côte d'Ivoire et causent plus de $90 \%$ des pertes de production liées aux parasites telluriques en Côte d'Ivoire (Lavigne, 1987). $R$. similis est un nématode foreur des pieds de bananier. Les mâles sont assez rares. La vulve est médiane, à 50 $\%$ ou $60 \%$ de la longueur du corps. Les tubes génitaux chez les femelles sont deux et développés. La queue chez les femelles est un peu conoïde et allongée, avec une terminaison arrondie ou indentée. La queue chez les mâles est allongée, conoïde, arquée ventralement. Les bourses s'étendent sur les deux tiers de la longueur de la queue (Siddiqi., 2000). Quant à P. coffeae, les mâles sont assez rares. La queue est convexe et conoïde. Les bourses s'étendent jusqu'à l'extrémité de la queue. La vulve est nettement postérieure, à $70 \%$ ou $80 \%$ de la longueur du corps. Seul le tube antérieur est développé chez les 
femelles. La queue chez les femelles est conoïde, ventralement concave. Les terminaisons sont grossièrement arrondies, tronquées ou irrégulièrement crénelées (Siddiqi., 2000).

\section{II.2. Methodes}

\section{II.2.1. Dispositif expérimental}

L'étude a été réalisée sur trois saisons de culture de bananier plantain. Lors du premier cycle de culture, les bananiers ont été plantés dans un dispositif de plantation en lignes jumelées à raison de 1,6 $\mathrm{m}$ sur la ligne et 2 $m$ entre une double ligne. Les lignes jumelées ont été séparées entre elles par des couloirs de $3 \mathrm{~m}$, donnant une densité de plantation de 2500 pieds/ha. L'essai est constitué de quatre blocs de culture, avec quatre parcelles élémentaires par bloc. Une parcelle élémentaire mesure $192 \mathrm{~m}^{2}$ soit $16 \mathrm{~m}$ x 12 $\mathrm{m}$. Elle est constituée de 56 plants dont 26 plants de bordure et 30 plants d'observations. Quatre traitements ont été distribués dans un bloc de Fisher complètement randomisé. Les traitements appliqués sont :

-Culture continue sans application de nématicide (Témoin), (CCNT) ;

-Culture continue avec application de nématicide de référence (Cadusafos 10\%), (CCT)

-Culture replantée à chaque fin de cycle, par déplacement de la ligne de culture avec application de nématicide (CRT) ;

-Culture replantée à chaque fin de cycle, par déplacement de la ligne de culture sans application de nématicide (CRNT).

\section{II.2.2. Conduite culturale}

Le planting s'est fait dans des trous de $30 \times 30$ x $40 \mathrm{~cm}$ de dimension. A la plantation, 166,6 g de dolomie et $133 \mathrm{~g}$ de phosphate tricalcique ont été apportés dans chaque trou de bananier comme engrais de fond. A partir de deux mois de végétation, $22 \mathrm{~g}$ d'urée $46 \%$ et $55 \mathrm{~g}$ de chlorure de potasse ont été appliqués en large couronne de $30 \mathrm{~cm}$ autour de chaque pied de bananier, chaque mois jusqu'à la floraison. Le nématicide Cadusafos $10 \%$ a été appliqué en couronne large de $30 \mathrm{~cm}$ autour des pieds de bananier à raison de $30 \mathrm{~g} /$ pied, à intervalle de trois mois ; septembre, décembre et mars à la $2^{\text {ème }}$ saison et octobre, janvier et avril à la $3^{\text {ème }}$ saison de culture. Le fongicide Chlorothalonil (720 g/l) a été appliqué sur les feuilles des bananiers pour 2 l/ha tous les 30 jours à partir du $4^{\text {ème }}$ mois, après plantation jusqu'à la fructification. Les parcelles ont été irriguées, goutte à goutte, cinq fois par semaine à raison de sept $\mathrm{mm}$ d'eau par jour. L'effeuillage a été réalisé au besoin lorsque les bananiers ont atteint un mètre de hauteur. L'œilletonnage a été réalisé mensuellement sur les pieds de bananier. Pour les parcelles en culture continue, un rejet successeur a été choisi à partir de la récolte. Un désherbage 
manuel a été réalisé chaque deux mois pour maintenir la parcelle propre. Chaque bananier a été tuteuré à la floraison.

\section{II.2.3. Suivi d'un gradient d'infestation le long du profile racinaire}

La replantation annuelle des bananiers a été faite dans les interlignes suivant un gradient d'infestations racinaire décroissant qui a servi d'indicateur à l'établissement des nouvelles lignes de plantation par rapport à celle de la culture précédente. Au $2^{\text {ème }}$ et $3^{\text {ème }}$ cycle de culture, le gradient d'infestation a consisté en un suivi régulier des populations de nématodes à deux distances à partir du pied fructifère entre 0 et $0,5 \mathrm{~m} ; 0,5 \mathrm{~m}$ et $1 \mathrm{~m}$ à $40 \mathrm{~cm}$ de profondeur.

\section{II.2.4. Méthodes d'échantillonnage des racines}

Les prélèvements de racines ont été faits au cours de trois stades végétatifs de développement des bananiers : en fin de la phase de croissance (à 182, 186 et 192 jours après plantation respectivement au premier, second et troisième cycle de culture), à $50 \%$ de floraison, soit à 243, 249 et 255 jours après plantation respectivement au premier, second et troisième cycle de culture et à $95 \%$ de récolte soit à 324 jours après plantation. A chaque stade végétatif, les échantillons ont été collectés selon la méthode de Tabarant (2013) en creusant une excavation de diamètre de [0 $\mathrm{m} ; 0,5 \mathrm{~m}$ [et] $0,5 \mathrm{~m} ; 1$ $\mathrm{m}$ [à $40 \mathrm{~cm}$ de profondeur tangentiellement à la souche du bananier plantain.

\section{II.2.5. Evaluation des rendements des bananiers}

Le régime de bananier est récolté 80 jours après floraison et pesé puis le poids rangé en fonction du traitement appliqué à la parcelle. Le rendement réel par traitement et par cycle de production $(\mathrm{kg})$ a été déterminé par la somme des masses du nombre de pieds de bananiers collectés par traitements. Le rendement réel par traitement et par cycle de production (kg) a été converti par pied récolté.

$$
\begin{gathered}
\mathbf{R}(\mathrm{Kg})=\Sigma \mathrm{Mn}(\mathrm{kg}) \\
\mathbf{R} / \mathbf{p i e d}=\Sigma \mathbf{M n} / \mathbf{n}(\mathrm{Kg})
\end{gathered}
$$

Avec, $\mathbf{M}$ : masse (Kg) du régime de bananier récolté ;

$\mathbf{n}$ : Nombre total de régimes de bananier récolté ;

$\mathbf{R}$ : Rendement réel des bananiers obtenu par traitement ;

R/pied : Rendement réel des bananiers obtenu par pied.

\section{II.2.6. Marge bénéficiaire relative aux deux techniques culturales de plantain de densité 2500 plants/ha}

La marge bénéficiaire a été évaluée et exprimée en F CFA. Elle a été basée sur le différentiel de revenu lié aux spécificités de charges. Seules les 
charges spécifiques à chaque technique culturale ont été prises en compte. Les charges d'investissement communes aux deux techniques de culture n'ont pas été prises en compte. Les charges sont l'ensemble des biens et services achetés et consommés du fait des besoins impartis à chaque technique culturale (Technique de replantation annuelle et technique de culture continue de bananiers). Elles concernent les charges opérationnelles ou variables. Leur évaluation a porté sur l'ensemble des charges spécifiques supportées par les exploitants au $2^{\text {ème }}$ et $3^{\text {ème }}$ cycle de production. Les charges spécifiques à la technique de culture replantée sont constituées des frais d'achat et du transport des vivoplants, de dessouchage, d'andainage, de piquetage, de trouaison et de planting. Les charges spécifiques à la technique de culture continue se composent des frais de sélection du rejet successeur, d'achat, du transport et des kits d'application et du coût de la main d'œuvre de l'application des nématicides (Tableau 1).

$$
\mathbf{C E R}=\mathbf{A ~ V}+\mathbf{T} \mathbf{V}+\mathbf{D} \mathbf{A}+\mathbf{P} \mathbf{T} \mathbf{P}
$$

Avec, C ER : Charges d'exploitation spécifiques à la culture replantée ;

A V : Frais d'achat des vivoplants ;

$\mathbf{T} \mathbf{V}$ : Frais de transport des vivoplants ;

D A : Frais de dessouchage et d'andainage ;

P T P : Frais de piquetage, trouaison et planting.

$$
\mathbf{C E C}=\mathbf{S} \mathbf{R}+\mathbf{A} \mathbf{N}+\mathbf{T} \mathbf{N}+\mathbf{A} \mathbf{K}+\mathbf{M} \mathbf{O}
$$

Avec, C EC : Charges d'exploitation spécifiques à la culture continue ;

$\mathbf{S} \mathbf{R}$ : Frais de sélection de rejet successeur;

A $\mathbf{N}$ : Frais d'achat des nématicides ;

$\mathbf{T} \mathbf{N}$ : Frais de transport des nématicides ;

A K : Frais d'achat des kits d'application des nématicides ;

M O : Coût de la main d'oeuvre de l'application des nématicides.

Tableau 1. Typologie de charges spécifiques à la culture replantée et continue pour la gestion des nématodes, pour une densité de 2500 plants/ha de bananier plantain

\begin{tabular}{|c|c|c|}
\hline Opérations Effectuées & $\begin{array}{c}\text { Charges spécifiques à la } \\
\text { technique de la culture } \\
\text { replantée bananier }\end{array}$ & $\begin{array}{c}\text { Charges spécifiques à la } \\
\text { technique de la culture } \\
\text { continue de bananier }\end{array}$ \\
\hline 1. Matériel végétal & $\begin{array}{c}\text { - Achat des vivoplants } \\
\text { - Transport des vivoplants }\end{array}$ & \\
\hline 2. Opérations Culturales & $\begin{array}{c}\text { - Piquetage, Trouaison et } \\
\text { planting } \\
\text { - Dessouchage et andainage }\end{array}$ & $\begin{array}{c}\text { - Sélection d'un rejet } \\
\text { successeur }\end{array}$ \\
\hline 3. Pesticides & & $\begin{array}{c}\text { - Achat des nématicides } \\
\text { - Transport des nématicides }\end{array}$ \\
\hline $\begin{array}{c}\text { 4. Kits d'application des } \\
\text { nématicides }\end{array}$ & $\begin{array}{c}\text { - Dosettes } \\
\text { - Achat de gants } \\
\text { - Achats de masques de }\end{array}$ \\
\hline
\end{tabular}




\begin{tabular}{|c|c|}
\hline & $\begin{array}{c}\text { protection } \\
\text { - Achats de seaux } \\
\text { - Combinaisons }\end{array}$ \\
\hline $\begin{array}{l}\text { 5. Main d'œuvre de } \\
\text { l'applicateur }\end{array}$ & $\begin{array}{l}\text { - Coût de la main d'œuvre } \\
\text { de l'application } \\
\text { - Tâches exécutées au cours } \\
\text { des opérations culturales }\end{array}$ \\
\hline
\end{tabular}

\section{II.2.7. Estimation des recettes de la vente des bananes plantain}

La vente des régimes de banane plantain a été considérée. Les régimes ont été récoltés en contre saison. Cette période de la faiblesse de l'offre des bananes sur les marchés a permis de créer une plus-value sur la vente des bananes plantain.

$$
\mathbf{M B}=\mathbf{R} \mathbf{E}-\mathbf{C} \mathbf{E}
$$

Avec, M B : Marge bénéficiaire ;

R E : Recettes d'exploitation ;

C E : Charges d'exploitation.

La performance économique de la technique de culture replantée de bananier plantain a été établie à partir de la différence de la marge bénéficiaire de la technique de culture replantée et celle de la culture continue.

\section{P E CR = M B CR - M B CC}

Avec, P E CR : Performance économique de la culture replantée de bananier plantain

M B CR : Marge bénéficiaire de la technique de culture replantée

M B CC : Marge bénéficiaire de la technique de culture continue

\section{II.2.8. Analyses statistiques}

Le logiciel STATISTICA 9.0 a été utilisé pour l'analyse des données. Les densités de nématodes ont été transformées en $\log (\mathrm{x}+1)$ et les proportions en $\operatorname{arc} \operatorname{sinus(x)}$ avant les analyses statistiques. Les analyses de variances et les moyennes ont été discriminées à l'aide du test de la Plus Petite Différence Significative au seuil de $5 \%$ de Fisher, P valeur seuil $5 \%$.

\section{Resultats}

\section{III.1. Effets des pratiques culturales sur le rendement}

La $1^{\text {ere }}$ saison de culture a enregistrée 30 t/ha. A la seconde saison de production, la replantation annuelle avec application de nématicide (CRT) (36,25 t/ha) ou sans traitement nématicide (CRNT) (35,08 t/ha) améliore le rendement par rapport à la culture continue avec $(30,75 \mathrm{t} / \mathrm{ha})$ ou sans traitement nématicide $(20,51 \mathrm{t} / \mathrm{ha})$. Ces différences de rendements sont statistiquement significatives $(\mathrm{P}<0,05)$ (Tableau 2). Comparativement au 
rendement obtenu au cours de la première année de culture (35 t/ha), la replantation annuelle avec et sans application de nématicide a permis de maintenir le niveau de production de $+3,58$ et $+0,23 \%$ respectivement en culture replantée avec application de nématicide (CRT) et en culture replantée sans application de nématicide (CRNT)]. En culture continue en revanche, des baisses de rendements ont été enregistrées et qui vont de $12,14 \%$ avec application (CCT) à 41,40 \% sans application de nématicide (CCNT). Au troisième cycle de culture, une baisse des rendements a été observée sur toutes les pratiques culturales. Une baisse de rendement de $0,40 \%$ a été notée avec la culture replantée avec application de nématicide (CRT), 2,11 \% en culture replantée sans application de nématicide (CRNT), 26,80 \% en culture continue avec application de nématicide (CCT) et de $62,57 \%$ en culture continue sans application de nématicide (CCNT) (Tableau 2). Les rendements sont tous statistiquement différents $(\mathrm{P}<0,05)$. Concernant les rendements au $2^{\text {ème }}$ et $3^{\text {ème }}$ cycle, la culture continue non traitée (CCNT), la culture continue traitée (CCT) et la culture replantée non traitée (CRNT) ont présenté une différence hautement significative $(\mathrm{P} \leq 0,05)$; contrairement à la culture replantée traitée où les rendements au $2^{\text {ème }}$ et $3^{\text {ème }}$ cycle sont sans différence significatives (Tableau 2).

Tableau 2. Rendements de bananier plantain du cultivar CORNE 1 en fonction des pratiques culturales au $2^{\text {ème }}$ et $3^{\text {ème }}$ saison de culture

\begin{tabular}{|c|c|c|c|c|}
\hline & \multicolumn{2}{|c|}{ Cycle de production } & \multicolumn{2}{c|}{ Rendements des bananiers (t/ha) } \\
\cline { 2 - 5 } & CCNT & CCT & CRNT & CRT \\
\hline Cycle 2 & $20,51 \pm 0,30 \mathrm{~d}^{\mathbf{a}}$ & $30,75 \pm 0,55 \mathrm{c}^{\mathbf{a}}$ & $35,08 \pm 0,30 \mathrm{~b}$ & $36,25 \pm 0,22 \mathbf{a}^{\mathbf{a}}$ \\
\hline Cycle 3 & $13,10 \pm 0,28 \mathrm{~d}^{\mathbf{b}}$ & $25,62 \pm 0,26 \mathbf{c}^{\mathbf{b}}$ & $34,26 \pm 0,39 \mathrm{~b}^{\mathbf{b}}$ & $34,86 \pm 0,35 \mathbf{a}^{\mathbf{a}}$ \\
\hline
\end{tabular}

*Les moyennes suivies d'une même lettre majuscule sur la même ligne ne sont pas statistiquement significatives au seuil de probabilité $5 \%$ (Test PPDS)

* Les moyennes suivies d'une même lettre minuscule en exposant sur la même colonne ne sont pas statistiquement significatives au seuil de probabilité 5 \% (Test PPDS de Fisher). ${ }^{*}$ CCNT : Culture continue non traitée ; CCT : Culture continue traitée ; CRNT : Culture replantée non traitée ; CRT : Culture replantée traitée.

\section{III.2. Charges d'exploitations spécifiques à la replantation d'un hectare de bananier plantain de densité 2500 plants/hectare}

Le coût d'acquisition des 2500 vivoplants plantés s'élève à $750000 \mathrm{~F}$ CFA en raison de 300 F CFA l'unité. Le coût du transport des 2500 vivoplants de bananiers plantains s'élève à $125000 \mathrm{~F}$ CFA à raison de $50 \mathrm{~F}$ CFA le transport d'un plant. Les charges liées à la mise en terre des semences de bananier se résument aux frais de dessouchage, d'andainage des résidus et rejets des bananiers du cycle de culture précédente, de piquetage, de trouaison et de planting dans les couloirs ou le niveau d'infestation est potentiellement faible. Le coût des frais de dessouchage et d'andainage des résidus et rejets des bananiers du cycle de culture précédente s'élève à 125000 F CFA. Le coût 
de piquetage, de trouaison et de mise en terre des vivoplants s'élève à 125000 F CFA. Le coût de piquetage, trouaison et de planting s'élève à 50 F CFA l'unité. Le total des charges inhérentes à la technique de replantation s'élève à $1125000 \mathrm{~F}$ CFA à la $2^{\text {eme }}$ saison de culture et $1125000 \mathrm{~F}$ CFA à la $3^{\text {ème }}$ saison de culture (Tableau 3).

\section{III.3. Charges d'exploitations spécifiques à la culture continue d'un hectare de bananier plantain de densité 2500 plants/ hectare}

Le coût des $225 \mathrm{~kg}$ de nématicide Cadusafos 10 \% nécessaires en culture continue, pendant une saison de culture s'élevé à 562500 F CFA en raison de $2500 \mathrm{~F}$ CFA le kilogramme de Cadusafos $10 \%$. Pour la mise en place de la $2^{\text {ème }}$ saison de culture, un rejet successeur a été sélectionné. Le coût de sélection des 2500 rejets s'élève à 62500 F CFA à raison de 25 F CFA par rejet sélectionné. Le coût de transport des nématicides au champ s'élève à 135 000 F CFA à raison de 600 F CFA/kg de nématicide. Quarante dosettes ont été nécessaires pour appliquer les $225 \mathrm{~kg}$ de nématicides. Le coût des dosettes pour appliquer les nématicides s'élève à 20000 FCFA à raison de 500 F CFA l'unité. Dix gants ont été acquis pour protéger les mains de l'applicateur. Le coût d'acquisition des gants s'élève à 10000 F CFA en raison de 1000 F CFA l'unité. Quatre masques de protection pour éviter aux applicateurs d'inhaler le nématicide Cadusafos $10 \%$ ont été utilisés. Le prix d'achat desdits masques s'élève à 100000 FCFA à raison de 25000 F CFA l'unité. Quatre combinaisons ont été utilisées pour protéger les applicateurs contre les effets nocifs du nématicide Cadusafos $10 \%$. Le coût d'acquisition des quatre combinaisons s'élève à 160000 FCFA à raison de 40000 F CFA l'unité. Quatre seaux de ménage ont été utilisés. Le coût des seaux qui ont servi à appliquer les nématicides en plantation s'élève à 4000 F CFA à raison de 1 000 F CFA l'unité. Les applicateurs ont mis 72 heures pour appliquer les nématicides. Le coût de la main d'œuvre de l'application s'élevé à $250000 \mathrm{~F}$ CFA à raison de 3472,23 F CFA/h. Le total des charges inhérentes à la technique de culture continue s'élève à 1304000 F CFA et 1304000 F CFA aussi bien à la $2^{\text {ème }}$ qu'à la $3^{\text {ème }}$ saison de culture (Tableau 3).

\section{III.4. Estimation des recettes de production spécifiques à la replantation et à la culture continue de $\mathbf{2} \mathbf{5 0 0}$ plants/ hectare de bananier plantain}

Les rendements obtenus par la technique de replantation sont estimés à $35030 \mathrm{Kg}$ et $30260 \mathrm{Kg}$ respectivement à la $2^{\text {ème }}$ et à la $3^{\text {ème }}$ saison. Ceux obtenus par la technique de culture continue sont de $20510 \mathrm{Kg}$ et $12790 \mathrm{Kg}$ respectivement à la $2^{\text {ème }}$ et à la $3^{\text {ème }}$ saison. Les recettes de la culture replantée de plantain sont estimées à $10509000 \mathrm{~F}$ CFA et $9078000 \mathrm{~F}$ CFA respectivement à la $2^{\text {ème }}$ et à la $3^{\text {ème }}$ saison contre 6153000 F CFA et 3837 
$000 \mathrm{~F}$ CFA respectivement à la $2^{\text {ème }}$ et à la $3^{\text {ème }}$ saison en culture continue (Tableau 3).

\section{III.5. Marge bénéficiaire de la culture replantée comparativement à la culture continue de densité 2500 plants/ hectare}

La marge bénéficiaire des recettes d'exploitation de chaque pratique culturale a été évaluée. Elle est estimée à 9384500 F CFA et $7953000 \mathrm{~F}$ CFA respectivement au $2^{\text {ème }}$ et $3^{\text {ème }}$ cycle en culture replantée contre 5703800 F CFA et $2587800 \mathrm{~F}$ CFA respectivement au $2^{\text {ème }}$ et $3^{\text {ème }}$ cycle en culture continue. La performance économique de la technique de la culture replantée comparée à celle de la culture continue est estimée à 2680700 F CFA et 3 $265200 \mathrm{~F}$ CFA respectivement au $2^{\text {ème }}$ et $3^{\text {ème }}$ cycle. La technique de replantation est économiquement bénéfique comparée à la technique de culture continue.

\begin{tabular}{|c|c|c|c|c|c|c|c|c|c|c|c|c|}
\hline \multirow{3}{*}{$\begin{array}{l}\text { Rubriques } \\
\text { 1. CHARGES }\end{array}$} & \multicolumn{6}{|c|}{ CULTURE REPLANTE } & \multicolumn{6}{|c|}{ CULTURE CONTINUE } \\
\hline & \multicolumn{3}{|c|}{ Saison 2} & \multicolumn{3}{|c|}{ Saison 3} & \multicolumn{3}{|c|}{ Saison 2} & \multicolumn{3}{|c|}{ Saison 3} \\
\hline & Quantité & $\begin{array}{c}\text { Prix } \\
\text { unitaire }\end{array}$ & Coût total & $\begin{array}{l}\text { Quanti } \\
\text { té }\end{array}$ & $\begin{array}{c}\text { Prix } \\
\text { unitai } \\
\text { re }\end{array}$ & Coût total & Quantité & $\begin{array}{c}\text { Prix } \\
\text { unitaire }\end{array}$ & Coût total & $\begin{array}{l}\text { Quantit } \\
\dot{e}\end{array}$ & $\begin{array}{c}\text { Prix } \\
\text { unitaire }\end{array}$ & Coût total \\
\hline $\begin{array}{l}\text { I.1. Matériel végétal } \\
\text { Yivoplants (pieds) } \\
\text { Transport des yuxerlants } \\
\text { (pied) }\end{array}$ & $\begin{array}{l}2500 \\
2500\end{array}$ & $\begin{array}{c}300 \\
50\end{array}$ & $\begin{array}{l}750000 \\
125000\end{array}$ & $\begin{array}{l}2500 \\
2500\end{array}$ & $\begin{array}{c}300 \\
50\end{array}$ & $\begin{array}{l}750000 \\
125000\end{array}$ & & & & & & \\
\hline $\begin{array}{l}\text { 1.2. Opérations culturales } \\
\text { Dessouchage et d'andainage } \\
\text { (pied) } \\
\text { Piquetage, trouaison et } \\
\text { planting } \\
\text { Sélection de rejets successeurs }\end{array}$ & $\begin{array}{l}2500 \\
2500\end{array}$ & $\begin{array}{l}50 \\
50\end{array}$ & $\begin{array}{l}125000 \\
125000\end{array}$ & $\begin{array}{l}2500 \\
2500\end{array}$ & $\begin{array}{l}50 \\
50\end{array}$ & $\begin{array}{l}125000 \\
125000\end{array}$ & 2500 & 25 & 62500 & 2500 & 25 & 62500 \\
\hline $\begin{array}{l}\text { 1.3. Achat des nématicides } \\
\text { Cadusafos } 10 \%(\mathrm{~kg}) \\
\text { Transport Cadusafos } 10 \%\end{array}$ & & & & & & & $\begin{array}{l}225 \\
225\end{array}$ & $\begin{array}{c}2500 \\
600\end{array}$ & $\begin{array}{l}562500 \\
135000\end{array}$ & $\begin{array}{l}225 \\
225\end{array}$ & $\begin{array}{c}2500 \\
600\end{array}$ & $\begin{array}{l}562500 \\
135000\end{array}$ \\
\hline $\begin{array}{l}\text { 1.4. Application nématicides } \\
\text { Dosettes } \\
\text { Main d'cuvre (heure) } \\
\text { Gants } \\
\text { Masques de protection } \\
\text { Bassinet "porte nématicide" } \\
\text { Combinaisons } \\
\text { Amortissement équipements }\end{array}$ & & & 1125000 & & & 1125000 & $\begin{array}{c}40 \\
24 \\
10 \\
4 \\
4 \\
4\end{array}$ & $\begin{array}{c}500 \\
10417 \\
1000 \\
25000 \\
1000 \\
40000\end{array}$ & $\begin{array}{c}20000 \\
250000 \\
10000 \\
100000 \\
4000 \\
160000 \\
54000 \\
1304000\end{array}$ & $\begin{array}{c}4 \\
24 \\
10 \\
4 \\
\\
4\end{array}$ & $\begin{array}{l}5000 \\
10417 \\
1000 \\
25000 \\
40000\end{array}$ & $\begin{array}{c}20000 \\
250008 \\
10000 \\
100000 \\
160000 \\
54000 \\
1304000\end{array}$ \\
\hline \multicolumn{13}{|l|}{ Total charges } \\
\hline $\begin{array}{c}\text { II. Produit } \\
\text { Recettes (rendement/kg) }\end{array}$ & 35030 & 300 & 10509000 & 30260 & 300 & 9078000 & 26510 & 300 & 7953000 & 19790 & 300 & 5937000 \\
\hline III. Marge Nette & & & 9384000 & & & 7953000 & & & 6649000 & & & 4633000 \\
\hline
\end{tabular}

\section{III.7. Discussion}

III.7.1. Performance économique de la technique de replantation de densité 2500 plants/hectare de bananiers plantain

La marge bénéficiaire en culture intensive de bananiers plantain s'obtient par la différence entre les charges opérationnelles de la culture replantée et la culture continue (produits et des charges d'exploitation). Ainsi, la marge bénéficiaire de la technique de replantation annuelle comparée à celle de la culture continue à partir d'une densité de plantation de 2500 plants à l'hectare a été évaluée. Les charges d'exploitation liées à la technique de la culture replantée sont estimées à 1125000 F CFA au $2^{\text {ème }}$ cycle et à 1125000 
F CFA au $3^{\text {ème }}$ cycle de culture. Celles liées à la technique de la culture continue s'élèvent à $1304000 \mathrm{~F} \mathrm{CFA} \mathrm{au} 2^{\text {ème }}$ et à $1304000 \mathrm{~F} \mathrm{CFA} \mathrm{au} 3^{\text {ème }}$ cycle de culture. La production a été faite en période de pénurie de banane plantain sur le marché, le kilogramme de banane a été marchandé dès lors à 300 F CFA. La production est estimée à 35030 et $30260 \mathrm{~kg}$ respectivement au $2^{\text {è̀me }}$ et $3^{\text {ème }}$ cycle en culture replantée et à 20510 et $12790 \mathrm{~kg}$ respectivement au $2^{\text {ème }}$ et $3^{\text {ème }}$ cycle en culture continue. Les recettes liées à la vente de la production se chiffrent respectivement à 10509000 et 9078000 F CFA en culture replantée respectivement au $2^{\text {ème }}$ et $3^{\text {ème }}$ cycle et à 5953000 et 3837000 respectivement au $2^{\text {ème }}$ et $3^{\text {ème }}$ cycle en culture continue. La marge bénéficiaire spécifique à la technique de replantation s'est élevée respectivement au $2^{\text {ème }}$ et $3^{\text {ème }}$ cycle à 9384500 et $7953000 \mathrm{~F}$ CFA et en culture continue respectivement au $2^{\text {ème }}$ et $3^{\text {ème }}$ cycle à 5703800 et 2587800 F CFA. Ainsi, la performance économique de la technique de replantation liée aux variations de la marge bénéficiaire de ladite technique et celle de la culture continue hormis les charges liées aux études d'impact environnemental se chiffre respectivement à 3680700 et $5365200 \mathrm{~F} \mathrm{CFA} \mathrm{à} \mathrm{la} 2^{\text {ème }}$ et $3^{\text {ème }}$ saison de culture. Bélalcazar et Cayon (1998) en Amérique Latine et au Caraïbes ont obtenus des marges bénéficiaires avec des rendements issus des densités élevées de 3000 plants/ha de plantation de bananiers plantain. En effet, avec des augmentations de plus de $50 \%$ de rendements, comparées aux densités classiques de 1667 plants/ha, une marge bénéficiaire de $500 \%$ a été enregistrée, comparée aux bananeraies à base de rejets attenants. Une telle performance économique de la culture replantée des bananiers plantain a été établie par Bélalcazar (1999), Bélalcazar et Cayon (2001), Adiko (2001) et Vawa et al (2015). En effet, selon eux, la production de la culture replantée de bananier plantain, à des densités de plus de 2500 plants/ha, exportées aux USA et dans l'Union Européenne génère des performances économiques de plus de 80 \% comparée à la production marchandée bord champ.

\section{Conclusion}

En définitive, la technique culturale novatrice basée sur la replantation annuelle des bananiers plantain est triplement avantageuse. Elle est économiquement rentable comparée à la culture pluriannuelle ; écologiquement intéressante car elle n'est pas inféodée à l'usage des nématicides et elle permet surtout de sédentariser les parcelles de bananiers (plus de trois saisons de culture) en gérant les peuplements de nématodes nuisibles. Pour avoir une étude beaucoup plus exhaustive dans l'optique de mieux apprécier la performance économique de la technique de replantation cyclique des bananiers, les charges inhérentes à l'étude d'impact environnementales devraient être intégrées dans l'élaboration de l'étude économique. Le conseil agricole devra promouvoir cette technique de 
replantation annuelle des bananiers plantains. Cette technique de replantation, sans avoir recours aux nématicides doit se faire avec du matériel de plantation sain (vitroplants) et planifier la production en période de pénurie de banane sur le marché de telle sorte à induire une plus-value sur le marchandage de la production.

\section{References:}

1. Adiko A. (2001). Amélioration des techniques culturales et de l'économie du plantain en Amérique Latine et les Caraïbes. Quelles perspectives pour l'Afrique de l'Ouest et du Centre. Rapport de mission en République Dominicaine et au Costa Rica. 22-29 Avril 2001, 18 p.

2. Belalcazar S. C. (1999). Practical guide for plantain production. Armenia, Quindio, Colombia. INIBAP-LAC, 38 p.

3. Belalcazar S. C., Cayon G. S. (1998). High-density planting. In proceedings of International seminar on plantain production. Armenia. Quindio, Columbia. 4 to 8 May 1998, 147-154.

4. Belalcazar S. C., Cayon G. S. (2001). High density planting. INIBAP. LAC, $9 \mathrm{p}$

5. Gnonhouri G. P., 2015. Communication personnelle.

6. Kobenan K., Traore S., Gnonhouri G. P., Yao T. (2006). Lutte intégrée contre la maladie des raies noires (MRN) du bananier plantain (Musa, $\mathrm{AAB}$, cv Orishele) sous différentes densités de plantation. Agronomie Africaine, 18 (2) : 157-163.

7. Kwa M. (1998). Production de rejets chez le bananier en cultures intensives. Fruits, 53 (6) : 365-374.

8. Lavigne C. (1987). Contribution à l'étude du système racinaire du bananier. Mise au point du rhizotron et premiers résultats. Fruits, 42 : 264-271.

9. Mounier Y. (1983). Végétation in " Les atlas jeune Afrique Côte d'ivoire". J. A, 16 -18 Pp, 78 p.

10. N'da A. A. (1993). La culture du bananier plantain au Cameroun et en Côte d'ivoire. Fruit, 4 (2) 125-132.

11. Nkendah R., Akyeampomg E., 2003. Données socioéconomiques sur la filière plantain en Afrique Centrale et de l'Ouest. InfoMusa, 12 (1): 8-12.

12. Sarah J. L. (2000). In: Diseases of banana, abaca and ensete. C.A.B International, Wallingford, Pp 295-303.

13. Siddiqi M. R., 2000. Tylenchida: parasites of plants and insects. CABI, Wallingford, UK, 833 p.

14. Tabarant P. (2013). Effets d'apport de matières organiques sur le contrôle biologique des nématodes parasites du bananier en 
Guadeloupe. Thèse de Doctorat Paris Technique. Institut des sciences et industries du vivant et de l'environnement, $176 \mathrm{p}$.

15. Thiemele D. E. F., Issali A. E., Traore S., Kouassi K. M., Aby N., Gnonhouri G. P., Kobenan K., Yao N. T., Adiko A., Zakra N. A. (2015). Macropropagation of plantain (Musa spp) cultivars PITA 3, FHIA 21, ORISHELE and CORNE 1: effect of benzylaminopurine (BAP) concentration. Journal Plant Development, 22: 31-39.

16. Vawa O. S. T., Gnonhouri G. P., Adiko A., Zakra N., Otchoumou A. (2015). La replantation annuelle du bananier plantain : une stratégie de gestion des nématodes endoparasites Radopholus similis et Pratylenchus coffeae en Côte d'Ivoire. 